\title{
Enhancing the Recyclability of a Vegetable Oil-Based Epoxy Thermoset through Initiator Influence
}

\author{
Chiara di Mauro, Thi-Nguyet Tran, Alain Graillot, and Alice Mija* \\ Cite This: ACS Sustainable Chem. Eng. 2020, 8, 7690-7700 \\ Read Online
}

ABSTRACT: Bisphenol A-based epoxy thermosets involve both environmental and health risks. By reacting a vegetal oil-based epoxide with an aromatic diacid containing $S-S$ bonds a thermoset is produced. Herein, reprocessable thermosets were synthesized, the recyclability being designed through a dual mechanism: that of disulfide metathesis and of transesterifications. To assess the feasibility of the reprocessing, a series of 10 initiators was tested to probe their effect not only on the cross-linking reaction but also on the recyclability. This study introduces for the first time the key role of the initiator on the material performance and on their reprocessing. A very good reprocessability was obtained for

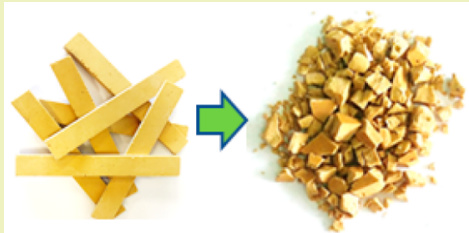

Bio-based Thermoset

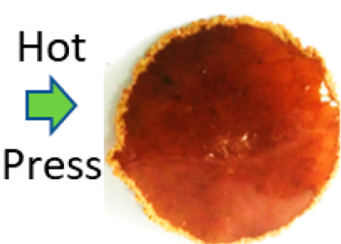

Recycled material

thermosets prepared using as initiator the imidazole. Moreover, the thermosets exhibit complete chemical recyclability in $1 \mathrm{~N}$ $\mathrm{NaOH}$ at $80^{\circ} \mathrm{C}$, after 3 days, without needing additional chemicals. The reprocessed materials have similar performance with the virgin ones, even after 10 cycles of reprocessing.

KEYWORDS: Epoxidized linseed oil, Dynamic hardener, Recyclability, Transesterification reaction, Disulfide exchange reaction

\section{INTRODUCTION}

The polymeric materials are mainly classified into two groups, as thermoplastic and thermosetting, in relation to their own properties when subjected to heating. The first group is formed by linear or slightly branched chains, and after increasing the temperature, they melt and can be reprocessed. Some of these materials are recyclable. The thermosetting materials include 3D networks like epoxy resins with excellent thermal and chemical stability; moreover, being constituted by cross-links and strong covalent bonds, the whole mobility of the macromolecule is limited. After cross-linking, the material becomes infusible and insoluble and its reprocessing impossible. Therefore, once damaged or at the end of life, the materials of the second group are treated as waste and disposed in landfills, leading to an increase of product costs and causing as well serious environmental and social consequences. For this reason, in recent years interest in recyclable and reprocessable plastics has grown increasingly, especially for thermosets ${ }^{1-9}$ and fiber-reinforced epoxy composites. To overcome the conventional problems of these polymers, a solution was found by introduction of dynamic interconnections in the thermoset network ${ }^{10-13}$ based on associative exchangeable covalent bonds in which the chemical linkages can be broken and reformed. Consequently, the dynamic character of the network is shown by changing its topology; otherwise, the number of cross-links established between inter- and intramolecular polymer chains remains constant. Leibler et al. ${ }^{14}$ pioneered a malleable and recyclable thermoset, called "vitrimer", by an epoxy-acid curing system. The underlying concept that allowed us to achieve this intrinsic property is based on a transesterification reaction. The authors demonstrated that the exchange reaction could be accelerated by catalysts such as 1,5,7-triazabicyclo[4.4.0] dec-5ene (TBD), ${ }^{15}$ 1,2-dimethylimidazole (1,2-DMI), ${ }^{16}$ or zinc acetate $\left(\mathrm{Zn}(\mathrm{OAc})_{2}\right) .{ }^{14}$ Qi et al. ${ }^{2}$ proved for diglycidyl ether of bisphenol A (DGEBA) and a mixture of fatty acids (Pripol $1040)$ system in the presence of $5 \mathrm{~mol} \%$ of $\mathrm{Zn}(\mathrm{OAc})_{2}$ that the reprocessing and recycling can be achieved. Along with transesterification, Odriozola et al. ${ }^{5,7}$ designed reshapable and recyclable thermosets by introducing disulfide dynamic chemical cross-links on DGEBA networks. The authors showed that the dynamic character of $S-S$ metathesis is also attractive because of its multiple responsive characteristics. For example, instead of a two-step process as in Diels-Alder exchange reactions, the self-healing of polymers containing S$S$ bonds can occur only in one step. ${ }^{17}$ By taking these advantages, we can design new epoxy thermosets with a dual intrinsic exchange mechanism. However, most of the above examples use DGEBA as epoxide monomer, which is prepared

Received: February 21, 2020

Revised: April 14, 2020

Published: April 22, 2020 


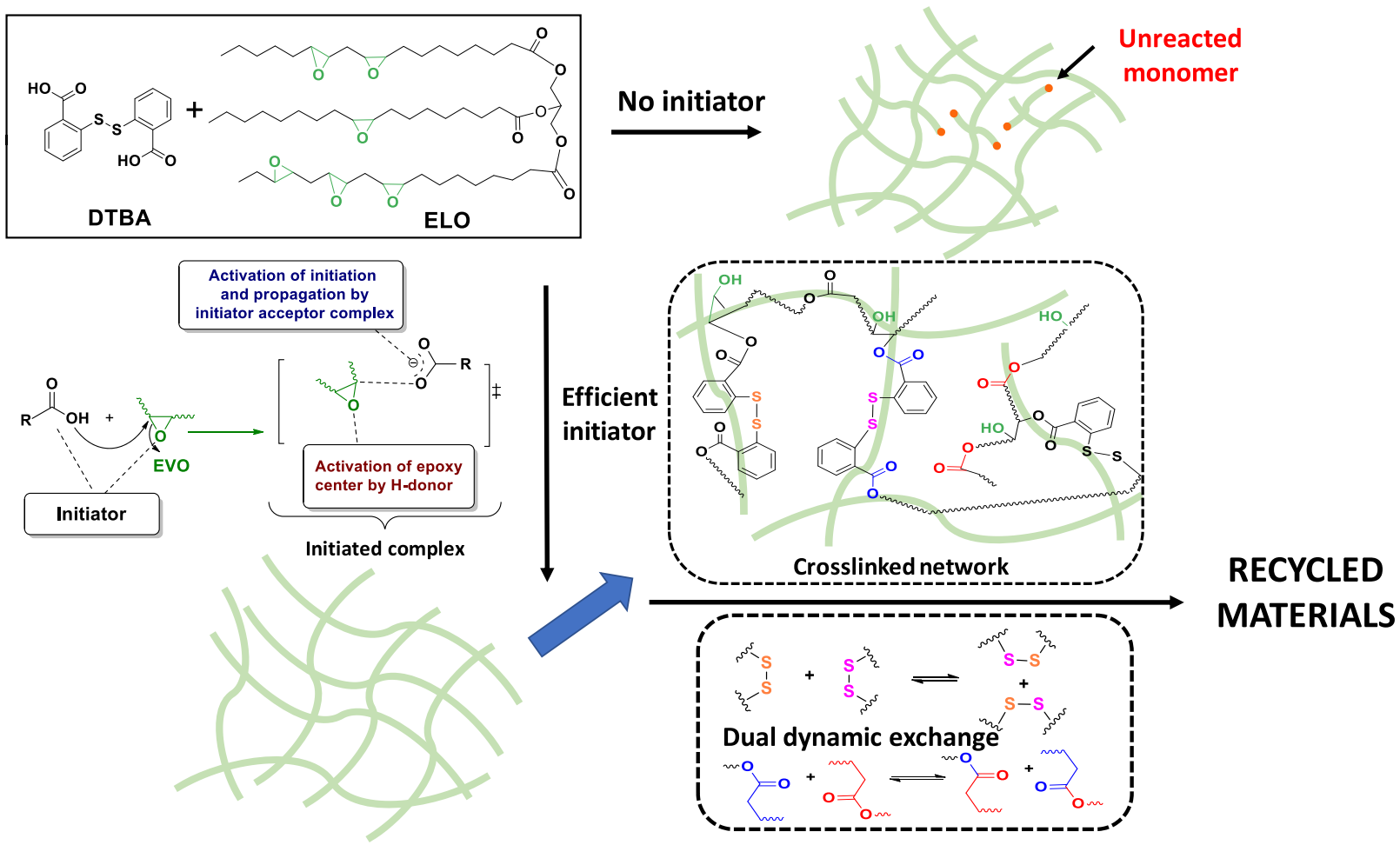

Figure 1. Synthesis of epoxidized linseed oil (ELO)/2,2'-dithiodibenzoic acid (DTBA) cross-linked structures, and network rearrangement by simultaneous exchange reactions: disulfide metathesis and carboxylate transesterification.

by the condensation reaction between bisphenol $\mathrm{A}(\mathrm{BPA})$ and epichlorohydrin. ${ }^{18-21}$ The harmful risk of $\mathrm{BPA}$ on the environment and especially on human health as an endocrine disruptors has been proved and published. ${ }^{22-24}$ Global ecological issues are requiring sustainable development of the polymer industry. For this reason, our attention focused on epoxidized vegetable oils, ${ }^{1,25-27}$ in particular, on epoxidized linseed oil (ELO), as starting materials due to their relatively low cost and high epoxy content. In this work, we report the preparation and characterization of new biobased recyclable and reprocessable epoxide thermosets using a disulfidecontaining dicarboxylic acid (DCA) as curing agent in the presence of several imidazole derivatives, $\mathrm{N}$-heterocyclic or amines, as initiators. To our knowledge, this study introduces for the first time the influence of the initiator on the reprocessing ability and on the thermosets performance. The objective of this study is to emphasize that the initiators not only play a key role on the epoxy-diacid copolymerization reaction but have a more extended impact. Therefore, their influence on the thermosets thermomechanical performance and recyclability is studied in this work. Three groups of nitrogen Lewis base initiators were selected. The first group includes two tertiary amines $N, N$-dimethylbenzylamine (DMBA) and 2,4,6-tris(dimethylaminomethyl) phenol (DMP30); this kind of initiator is currently used for the epoxy ring opening. The second group comprises the heterocyclic nitrogen initiators including dimethylaminopyridine (DMAP), imidazole (IM), 1-methylpiperazine (1-MP), and 1,5,7-triazabicyclo[4.4.0] dec-5-ene (TBD). Finally, the last group focuses on the imidazole and its derivatives. Imidazole was initially selected as the reference initiator due to its high reactivity and relatively low cost. ${ }^{28-32} \mathrm{IM}$ is an amphoteric molecule behaving both as a donor and as an acceptor center with two nitrogen atoms. To comprehend how the substituent groups on the imidazole ring have an influence on the reaction and network behavior, 1-N- and 2-N-substituted imidazoles were studied. The prepared networks, containing $\mathrm{S}-\mathrm{S}$ dynamic bonds via the hardener structure, are therefore able to rearrange by dual-simultaneous exchange reactions: disulfide metathesis and carboxylate transesterification. The thermoset synthesis, the role of the initiators, and the network reprocessing are illustrated in Figure 1. The reactivity study of the novel formulations was realized by in situ Fourier transform infrared spectroscopy (FTIR) and differential scanning calorimetry (DSC). The physical and thermomechanical properties of the virgin thermosets and of the reprocessed materials were analyzed by DSC, thermogravimetric analysis (TGA), and dynamic mechanical analysis (DMA).

\section{MATERIALS AND METHODS}

Materials. The initiator structures used in this study are shown in Figure 2.

The epoxidized linseed oil (ELO) was obtained by Valtris Specialty Chemicals. The hardener and all of the initiators were purchased from Sigma-Aldrich and used as received without further purification: DTBA (2,2'-dithiodibenzoic acid, 95\%), IM (imidazole, 99\%) (Figure

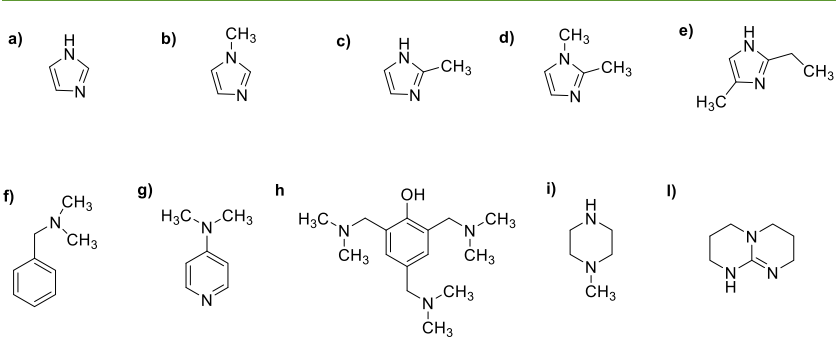

Figure 2. Chemical structure of 10 studied initiators. 

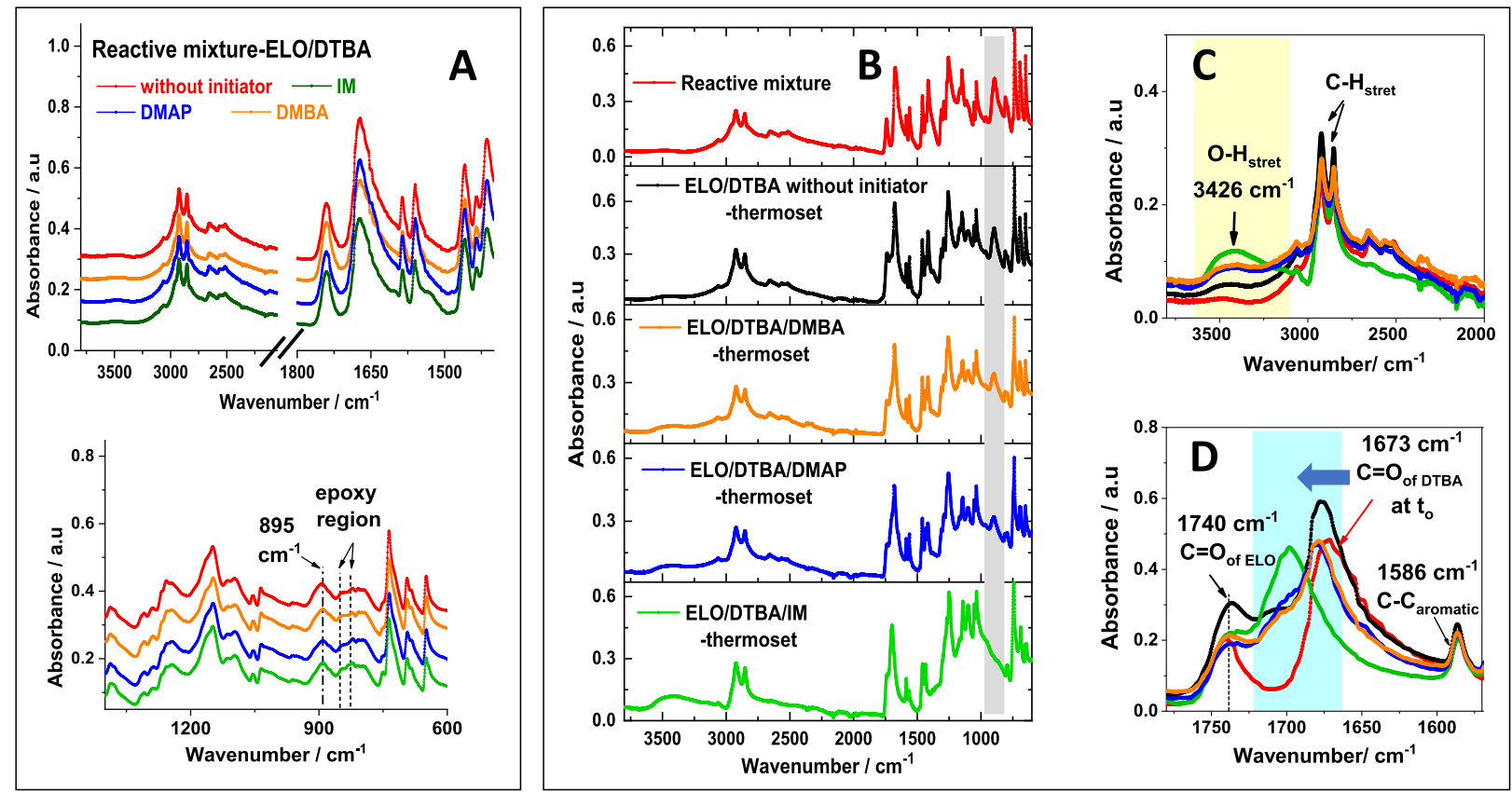

Figure 3. (A) Comparison between the FTIR spectra of the ELO/DTBA reactive mixture without initiator and that of the ELO/DTBA reactive mixture with DMBA, DMAP, and IM. (B-D) FITR spectra of ELO/DTBA final thermosets in comparison to reactive mixture: (B) whole spectrum; (C) zoom in the region $3800-2000 \mathrm{~cm}^{-1}$; (D) zoom in the region $1780-1570 \mathrm{~cm}^{-1}$.

2a), 1-MI (1-methylimidazole, 99\%) (Figure 2b), 2-MI (2methylimidazole, 99\%) (Figure 2c), 1,2-DMI (1,2-dimethylimidazole, 97\%) (Figure 2d), 2E4MI (2-ethyl 4-methylimidazole, 95\%), (Figure 2e), DMBA ( $N, N$-dimethylbenzylamine, 99\%) (Figure 2f), DMAP (dimethylaminopyridine, 99\%) (Figure 2g), DMP30 (2,4,6-tris(dimethylaminomethyl) phenol, 95\%) (Figure 2h), 1-MP (1methylpiperazine, 99\%) (Figure 2i), and TBD (1,5,7triazabicyclo[4.4.0] dec-5-ene, 98\%) (Figure 2j). The reagents structure and their physicochemical characteristics are summarized in Table S1.

Samples Preparation. The curing formulations were prepared at a 1:1 ratio between epoxy and acid groups, according with Dusek et al. ${ }^{33}$ First, the epoxy monomer was heated to around $80{ }^{\circ} \mathrm{C}$ to decrease the viscosity. Thereafter, the selected initiator was added at 1 wt $\%$ and mixed until homogenization. At this point the mixture was introduced to the hardener. Each formulation was stirred at $80{ }^{\circ} \mathrm{C}$ for $10 \mathrm{~min}$, placed into a silicone mold, and cured in an oven. The curing and postcuring protocols for preparation of the thermosets were determined based on a DSC study of the reactivity (Figure S1), the protocol being displayed in Table S2.

According to this procedure, the samples for DMA analysis were prepared in special rectangular molds.

Analytical Methods. Differential Scanning Calorimetry (DSC). DSC measurements were carried out on a Mettler-Toledo DSC 3 apparatus controlled by STAR Software developed by Mettler-Toledo. The instrument heat flow and temperature were calibrated in 3 points using water, indium, and zinc standards. Samples of 8-12 mg were placed into $40 \mu \mathrm{L}$ aluminum crucibles. The DSC was used for study of the copolymerization reactivity and the glass transition of the obtained resins using a heating rate $\beta$ of $10{ }^{\circ} \mathrm{C} \cdot \mathrm{min}^{-1}$ over a temperature range from 0 to $220{ }^{\circ} \mathrm{C}$ for the copolymerizations and from -80 to $180^{\circ} \mathrm{C}$ for the $T_{\mathrm{g}}$ studies.

Fourier Transform Infrared Spectroscopy (FTIR). The FT-IR spectra of the samples were recorded using a Thermo Scientific Nicolet iS50 FT-IR spectrometer with a deuterated L-alanine-doped triglycine sulfate (DLaTGS) detector in attenuated total reflectance (ATR) mode. The absorption bands were recorded in the range of $4000-525 \mathrm{~cm}^{-1}$ with 32 scans and a resolution of $4 \mathrm{~cm}^{-1}$. The data were analyzed using OMNIC software. Conversion of functional groups at time $(t)$ is denoted as percent and defined by eq 1

$$
\%=\frac{\left(\frac{A_{\text {functional groups }}}{A_{1586}}\right) 0-\left(\frac{A_{\text {functional groups }}}{A_{1586}}\right) t}{\left(\frac{A_{\text {functional groups }}}{A_{1586}}\right) 0} \times 100
$$

The area absorbance peaks were calculated and reported at the initial time $\left(A_{0}\right)$ and at different times $\left(A_{t}\right)$. The selected peak at about 823 $\mathrm{cm}^{-1}$ corresponds to the oxirane $\mathrm{C}-\mathrm{O}$ groups, that at $895 \mathrm{~cm}^{-1}$ corresponds to carboxylic groups, while the peak at $1586 \mathrm{~cm}^{-1}$ is the reference band belonging to the $\delta_{\mathrm{C}=\mathrm{C}}$ of the aromatic signal.

Thermogravimetric Analysis (TGA). TGA measurements were carried out on a Mettler-Toledo TGA 2. The microbalance has a precision of $\pm 0.1 \mu \mathrm{g}$. Samples of about $10 \mathrm{mg}$ were placed into $70 \mu \mathrm{L}$ alumina pans. To characterize the thermal stability of the thermosets, the samples were heated at $10{ }^{\circ} \mathrm{C} \cdot \mathrm{min}^{-1}$ from 25 to $1000^{\circ} \mathrm{C}$ under 50 mL.min ${ }^{-1}$ air flow.

Dynamic Mechanical Analysis (DMA). DMA analyses were performed using a Mettler-Toledo DMA 1 instrument equipped with STAR software. The analyzed samples had rectangular dimensions of $30 \times 7 \times 2 \mathrm{~mm}^{3}$ (length $\times$ width $\times$ thickness). Each thermoset system was analyzed 3 times, and the values were averaged. The DMA was operated in the temperature-scanning mode with a constant displacement amplitude and frequency using the tension method for analysis of virgin and recycled materials. Elastic modulus values $\left(E^{\prime}\right)$ and damping factor $(\tan \delta)$ were collected at a $3{ }^{\circ} \mathrm{C} \cdot \mathrm{min}^{-1}$ heating rate from -80 to $170{ }^{\circ} \mathrm{C}$ and $1.0 \mathrm{~Hz}$ frequency. The glass transition value was assigned at the maximum of damping factor ( $\tan$ $\delta=E^{\prime \prime} E^{\prime}$.

Cross-linking density was calculated by eq 2

$$
v=\frac{E^{\prime}}{3 R T}
$$

where $E^{\prime}$ is the storage modulus of the thermoset in the rubbery plateau region at $T_{\mathrm{g}}+50{ }^{\circ} \mathrm{C}, \mathrm{R}$ is the gas constant, and $T$ is the absolute temperature in Kelvin. The obtained value was used to calculate the molecular weight $\left(M_{c}\right)$ of the segment chains between the cross-links

$$
M_{\mathrm{c}}=\frac{\delta}{v}
$$


where $\delta$ is the density of the thermoset resin.

Density Calculation. The sample densities were determined by measuring the volume of each sample and its weight obtained using a Mettler Toledo ML $3002 \mathrm{~T}$ precision balance $( \pm 0.0001 \mathrm{~g})$.

Solvent Stability. The resin swelling test was performed in different solvents: methanol, acetone, and toluene. A piece of each material (virgin and reprocessed) was left in the selected solvents for $24 \mathrm{~h}$, and the weight was followed over the time. The swelling factor was calculated according to eq 4

$$
Q=\frac{m_{\mathrm{s}}-m_{\mathrm{u}}}{m_{\mathrm{u}}}
$$

where $m_{\mathrm{s}}$ and $m_{\mathrm{u}}$ are the swollen and unswollen sample mass. The same procedure was applied for virgin and reprocessed materials. The materials solvent stability was also studied in stronger solvents as tetrahydrofuran, dimethyl sulfoxide, $1 \mathrm{~N} \mathrm{NaOH}$, and $1 \mathrm{~N} \mathrm{HCl}$ for 3 days at $80{ }^{\circ} \mathrm{C}$.

Reprocessing Procedure. To test the mechanical reprocessing, the cross-linked thermosets were reduced in small pieces. Thereafter, the obtained grinded material was compressed between two Kapton films and reprocessed with the help of a CARVER manual heating press at temperatures in the range $150-170{ }^{\circ} \mathrm{C}$ under a pressure of $\sim 60$ bar.

\section{RESULTS AND DISCUSSION}

The protocol of the curing and postcuring processes was determined for each formulation by differential scanning calorimetry DSC studies (Figure S1 and Table S2). An equimolar ratio between acid and epoxide functional groups was used for preparing the formulations. Ten initiators were selected to study their effect on the curing reaction. An initiator percentage of $1 \%$ of mixture mass was found as optimal, as studied and deduced in a previous study. ${ }^{34}$ As highlighted in Table S2, the ELO-DTBA cross-linking study illustrates the initiator efficiency by lowering the activation energy of the reaction and accelerating the curing rate. Due to a very low reactivity, the noninitiated system was discarded.

Structural Investigation of ELO/DTBA Copolymerization by FTIR. To highlight the structural evolutions between the initial ELO/DTBA reactive mixtures and those of the final thermosets a series of FTIR analyses was performed. To these studies was added the comparison with the systems (mixtures or thermosets) prepared with or without the selected initiators. The obtained results are presented in Figure 3. Considering that only $1.0 \mathrm{wt} \%$ of initiator is present in the reactive mixture, Figure 3 A shows that all ELO/DTBA systems, with and without initiators, have similar spectra. Therefore, the initiator signals are negligible compared to that of ELO and DTBA.

In the spectra of reactive mixtures, the characteristic peaks of the epoxy groups appear at 823 and $847 \mathrm{~cm}^{-132,35,36}$ while those of the carboxylic groups, with very broad vibration bands, are in the region of 3300-2300 and at $895 \mathrm{~cm}^{-1}$ assigned, respectively, to the $\mathrm{O}-\mathrm{H}$ stretching and $\mathrm{O}-\mathrm{H}$ bending of the $-\mathrm{COOH}$ groups. Other characteristic peaks are observed including the $-\mathrm{C}=\mathrm{O}$ stretching of triglycerides' ester of ELO at 1740 and $1673 \mathrm{~cm}^{-1}$ attributed to $-\mathrm{C}=\mathrm{O}$ stretching of DTBA. Compared with these reference peaks, we notice in the FTIR spectra of all ELO/DTBA thermosets complete disappearance of the oxirane peaks ( 823 and 847 $\mathrm{cm}^{-1}$ ) along with the appearance of the $-\mathrm{OH}$ band at 3550 $\mathrm{cm}^{-1}$. This result demonstrates a complete epoxide ring opening via nucleophilic addition. By introduction of DTBA acid as a hardener in the ELO network, the carbonyl stretching band $(\mathrm{C}=\mathrm{O})$ is shifted from $1673 \mathrm{~cm}^{-1}$ in DTBA to higher frequency at about $1700 \mathrm{~cm}^{-1}$ for the newly created ester (Figure 3D). This peak is proof of ester bond formation by
ELO/DTBA thermocuring copolymerization. However, at the same time, other side reactions could involve the residual epoxy functions via homopolymerization or etherifications. $^{37-40}$ Depending strongly on the initiator efficiency, these secondary reactions can be dismissed. As shown in Figure $3 \mathrm{~B}$, in the presence of $1 \%$ of IM, complete copolymerization was achieved as confirmed by the complete disappearance of the epoxide and of the $-\mathrm{OH}$ from $-\mathrm{COOH}$. In the FTIR spectra of ELO/DTBA/No initiator thermoset or that with inefficient initiators, like DMBA or 1-MP, we can observe that the epoxide absorptions at 847 and $823 \mathrm{~cm}^{-1}$ disappear completely while the $\mathrm{O}-\mathrm{H}$ band of the carboxylic acid at $895 \mathrm{~cm}^{-1}$ is still present. For example, $\sim 50 \%$ of $-\mathrm{COOH}$ remains unreacted in the ELO/DTBA/No initiator or ELO/DTBA/DMBA thermoset system. This result indicates extra consumption of epoxy groups in comparison to that of the $-\mathrm{COOH}$ groups, meaning secondary reactions like etherifications occur. ${ }^{41}$ On the basis of this observation, copolymerization conversion was quantified by the peak area of the $-\mathrm{OH}$ absorption of the carboxylic functions at about $895 \mathrm{~cm}^{-1}$ with reference to the aromatic peak at about 1586 $\mathrm{cm}^{-1}$ corresponding to $\mathrm{C}=\mathrm{C}$ stretching of the aromatic ring. The obtained results are presented in Figure 4 and discussed in detail in the next section.

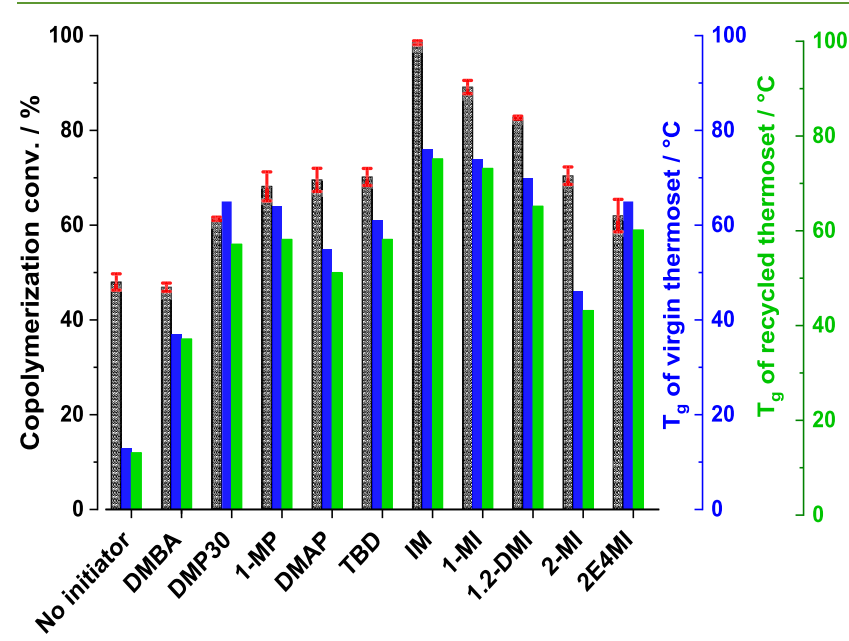

Figure 4. Comparison between virgin and reprocessed ELO/DTBA/ Initiators thermosets: $T_{g}$ values of virgin (blue) and reprocessed (green) thermosets determined by DSC analysis correlated with the copolymerization conversion (black) as calculated by FTIR analysis. In the abscissa are indicated the initiators used for each ELO/DTBA/ Initiator system.

Thermomechanical Analyses of ELO/DTBA Thermosets: Comparison of Virgin and Recycled Materials. The present work studies the ability of synthesized thermosets to be reprocessable and recyclable and to analyze how the materials properties are affected by the reprocessing. Table S5 summarizes the reprocessing parameters applied for each system to obtain a completely reprocessed sample. As illustrated in Table S7, the prepared thermosets have good reprocessability that can be attributed to the combination of two mechanisms: dynamic disulfide bonds and transesterification exchange as schematized in Figure 1. The temperature, pressure, and time needed for recycling the ELO/DTBA thermosets are lower compared with those reported for 

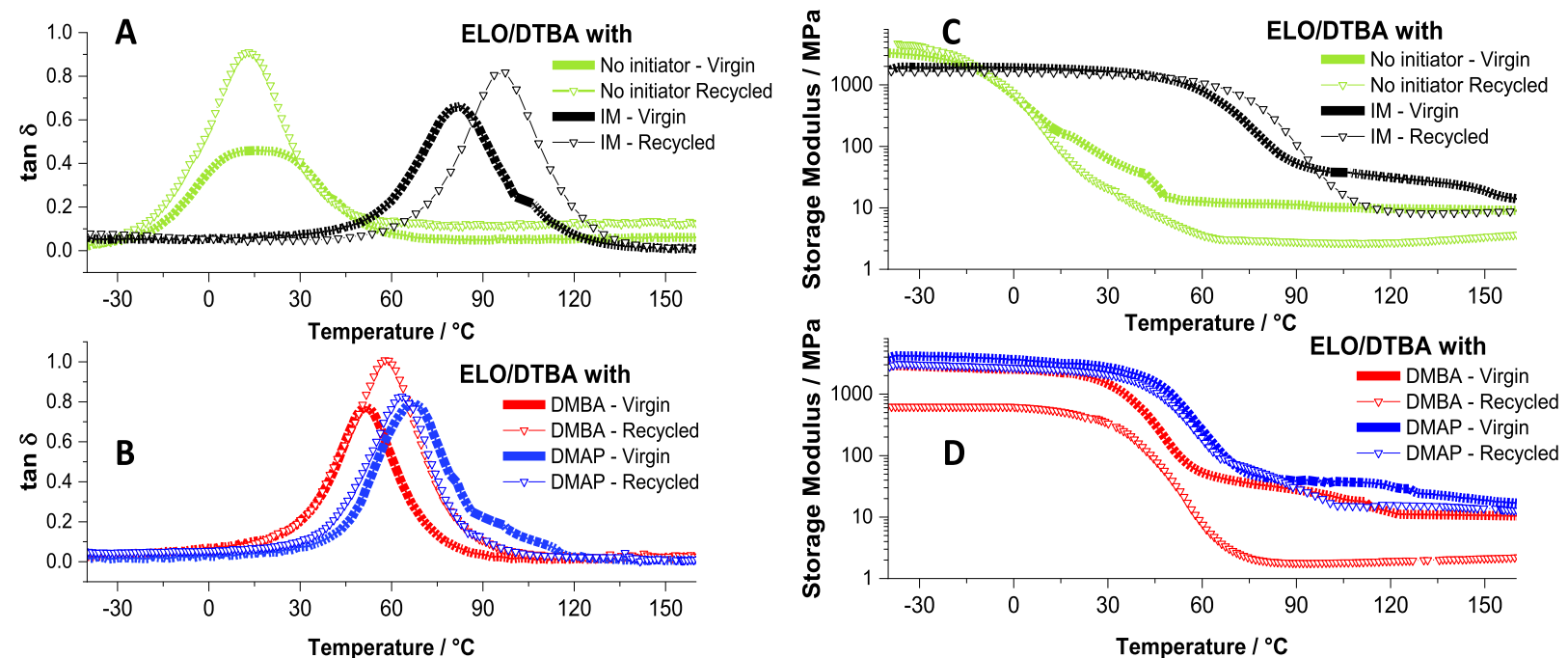

Figure 5. DMA results: $\tan \delta$ and storage modulus vs temperature of thermosets and reprocessed samples as a function of the initiators: (A and C) uncatalyzed thermosets and ELO/DTBA/IM; (B and D) uncatalyzed thermosets and ELO/DTBA/DMBA and ELO/DTBA/DMAP.

DGEBA/4-aminophenyl disulfide (AFD) thermosets that require a hot pressing at $200{ }^{\circ} \mathrm{C}$ and 100 bar for $5 \mathrm{~min}^{7}$

It is well known that the polymer architecture topology is deeply affected by the side reactions that can occur during network building. For example, the etherification reactions can introduce some branching points, therefore changing the network cross-link density and thus impacting the final properties. To evaluate the initiator influence on the network properties, the $T_{\mathrm{g}}$ transitions were evaluated by DSC. The obtained results are given in Figure 4, where we compare the glass transitions of ELO/DTBA thermosets synthesized with and without initiator. In the same figure we report also the conversion of copolymerization, determined by FTIR.

Figure 4 illustrates very well the strong impact of the initiator nature on the properties of the synthesized thermosets. The efficiency of the initiator not only controls the copolymerization mechanism but impacts the network building, architecture, and so overall performance. It can be observed in Figure 4 that the virgin thermosets present a large variety of $T_{\mathrm{g}}$ from 13 to $76^{\circ} \mathrm{C}$ for the thermoset prepared without or with IM, respectively. Use of epoxidized vegetable oil, with an aliphatic structure, formed materials with lower $T_{g}$ compared to those of DGEBA-based thermosets. Considering the reprocessable systems, values of $T_{\mathrm{g}} \approx 130{ }^{\circ} \mathrm{C}$ were reported for a DGEBA/4-aminophenyl disulfide (AFD) thermoset. $^{5}$ Zhang et al. ${ }^{15}$ produced vitrimers based on DGEBA/4, $4^{\prime}$-dithiodibutyric acid (DTDA) with $T_{\mathrm{g}} \approx 30{ }^{\circ} \mathrm{C}$. The impact of the aliphatic epoxide on the material properties was studied by Altuna et al. ${ }^{42}$ for DGEBA mixed with different amounts of epoxidized soybean oil (ESO). This epoxide mixture was cured with methyltetrahydrophthalic anhydride (MTHPA) in the presence of 1-MI initiator. The authors show that the $\tan \delta$ values decrease with ESO content from 108 to $57{ }^{\circ} \mathrm{C}$ for the fully ESO thermoset. Compared to these results, we report in this work that by initiator influence we can modulate the $T_{\mathrm{g}}$ from $13{ }^{\circ} \mathrm{C}$ for ELO/DTBA/without initiator to $\sim 76{ }^{\circ} \mathrm{C}$ for ELO/DTBA/IM thermoset.

The obtained thermomechanical properties were compared with that of the recycled materials. After reprocessing, similar values were measured with a small decrease of $T_{\mathrm{g}}$ for all of the studied systems (difference $\Delta T_{\mathrm{g}} \leq 9^{\circ} \mathrm{C}$ ). In the same trend as
ELO/DTBA uncatalyzed virgin thermoset, its reprocessed material also exhibits the lowest $T_{\mathrm{g}}\left(\sim 12{ }^{\circ} \mathrm{C}\right)$ combined with the lowest copolymerization conversion; only $\sim 50 \%$ of $-\mathrm{COOH}$ was converted. This result suggests a heterogeneous thermoset network characterized by pending unbonded chains of triglyceride and dicarboxylic acid. In contrast, the systems with $1 \mathrm{wt} \%$ initiator show higher $T_{\mathrm{g}}$ values before or after reprocessing. In the imidazole series, the synthesized thermosets have comparable $T_{\mathrm{g}}$ values, except the system with 2-MI that presents a low $T_{\mathrm{g}}$. A similar behavior was reported by Such et al. $^{43}$ for the curing of the diglycidyl ether of bisphenol A initiated by different imidazoles. According to this study, the lower $T_{\mathrm{g}}$ of the network obtained in the presence of 2-MI was attributed to a plasticizing effect of the initiator. Figure 4 shows that the 2E4MI system displays a lower copolymerization conversion in the imidazole series.

In the case of thermosets systems with 1-MP and DMP30, reprocessing was more difficult, requiring a longer time and a higher temperature. Among the 10 catalyzed thermosets, ELO/DTBA/DMBA exhibits a lower $T_{\mathrm{g}} \approx 37^{\circ} \mathrm{C}$ for the virgin and $T_{\mathrm{g}} \approx 36{ }^{\circ} \mathrm{C}$ for the recycled material. This result could be first related to the copolymerization conversion with only $\sim 50 \%$ of carboxylic functions converted in ester bonding with the ELO network (Figure 4). Therefore, it can be also correlated to a low cross-linking density that allows a certain chain mobility and consequently a low $T_{\mathrm{g}}$ value. $\mathrm{Hu}$ et al. ${ }^{44}$ report that the glass transition decreases during the reprocessing by decreasing the network cross-linking.

To evaluate if structural modifications occur in the thermoset network during the reprocessing, FTIR analyses were performed before and after mechanical recycling. The obtained results show that no changes occur after reprocessing; similar spectra for virgin and recycled thermoset are obtained. This observation was confirmed by complementary experiments, as illustrated in Figure S2, by an isothermal FTIR study at $170{ }^{\circ} \mathrm{C}$ (reprocessing temperature) at which no difference was detected even after $90 \mathrm{~min}$.

Dynamic Mechanical Analysis. To analyze the viscoelastic properties, the following thermoset systems were selected: ELO/DTBA/IM, ELO/DTBA/DMBA, and ELO/ DTBA/DMAP. The storage modulus $\left(E^{\prime}\right)$ values and loss 
Table 1. Mechanical Properties of Virgin and Reprocessed ELO/DTBA Thermosets

\begin{tabular}{|c|c|c|c|c|c|c|c|c|}
\hline & \multicolumn{2}{|c|}{ no initiator } & \multicolumn{2}{|c|}{ IM } & \multicolumn{2}{|c|}{ DMBA } & \multicolumn{2}{|c|}{ DMAP } \\
\hline & virgin & recycled & virgin & recycled & virgin & recycled & virgin & recycled \\
\hline $\tan \delta^{a}\left({ }^{\circ} \mathrm{C}\right)$ & 15 & 13 & 83 & 97 & 52 & 58 & 66 & 63 \\
\hline$(\tan \delta)^{a}{ }_{\max }$ & 0.45 & 0.91 & 0.66 & 0.82 & 0.77 & 1.0 & 0.79 & 0.83 \\
\hline$E^{\prime a}$ at $-50{ }^{\circ} \mathrm{C}(\mathrm{MPa})$ & 3390 & 4730 & 1560 & 2550 & 2660 & 700 & 2380 & 2600 \\
\hline$E^{\prime a}$ at $160^{\circ} \mathrm{C}(\mathrm{MPa})$ & 9 & 3 & 16 & 9 & 8 & 2 & 7 & 4 \\
\hline cross-linking density ${ }^{a}\left(\mathrm{mmol} / \mathrm{cm}^{3}\right)$ & 0.82 & 0.30 & 1.25 & 0.81 & 0.98 & 0.21 & 1.18 & 0.79 \\
\hline density $\left(\mathrm{g} / \mathrm{cm}^{3}\right)$ & 0.905 & & 1.025 & & 0.896 & & 0.913 & \\
\hline$M_{\mathrm{c}}^{a}(\mathrm{~g} / \mathrm{mol})$ & 1104 & & 820 & & 914 & & 774 & \\
\hline
\end{tabular}

${ }^{a}$ Determined by DMA. ${ }^{b}$ Determined by the mass/volume ratio.

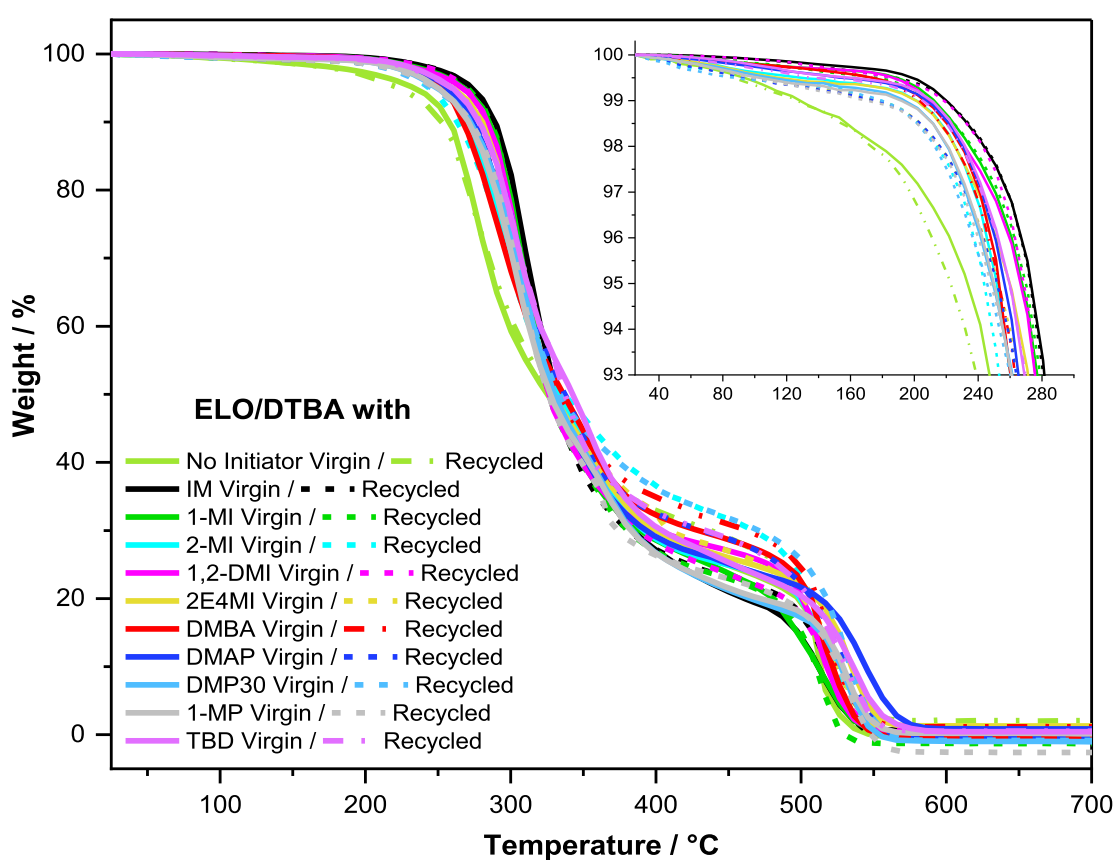

Figure 6. TGA comparison between the virgin and the recycled resins with and without initiators.

factor $(\tan \delta)$ curves of these systems are presented as a function of temperature in Figure 5. The $\tan \delta$-correlated to the $\alpha$ relaxations and associated with the macroscopic glass transition $\left(T_{\mathrm{g}}\right)$-were determined, ranging from 15 to $89{ }^{\circ} \mathrm{C}$. A similar range of $T_{\mathrm{g}}$ was reported by Gobin et al. ${ }^{45}$ with a $T_{\mathrm{g}}$ $\approx 16{ }^{\circ} \mathrm{C}$ for epoxidized broccoli oil cross-linked with $o$ phenylene diacetic acid in the absence of initiator. In comparison with ELO/aliphatic diacid thermosets, ${ }^{32}$ the $\tan$ $\delta$ values are higher for ELO/DTBA networks due to the presence of the aromatic structure of DTBA cross-linker introducing rigid segments. The $\tan \delta$ of the noncatalyzed system exhibits the lowest value; meanwhile, the system has the highest storage modulus (Figure 5). The associated $T_{\mathrm{g}}$ values obtained by DSC for the virgin and recycled thermosets are in the same trend with that measured by DMA. These results indicate that the initiated systems exhibit higher $\tan \delta$ and $T_{\mathrm{g}}$. After mechanical recycling, the ELO/DTBA/IM thermoset displays the highest $\tan \delta \approx 97{ }^{\circ} \mathrm{C}$ while DMBA is confirmed again as a less efficient catalyst with produced thermosets having $\tan \delta \approx 58{ }^{\circ} \mathrm{C}$ combined with the higher decrease in the storage modulus through the rubbery plateau.

The thermosets cross-link density was calculated using the $E^{\prime}$ value in the rubbery plateau according to eq 2 . As illustrated in Tables 1 and S6, depending on the initiator nature, the cross-link densities vary from 1.91 to $0.82 \mathrm{mmol} / \mathrm{cm}^{3}$. Among the 10 initiators (Figures S4 and S5), DMP30 and 2E4MI allow us to produce thermosets with the highest cross-link density; nevertheless, these values decrease drastically after reprocessing: $1.97 \mathrm{mmol} / \mathrm{cm}^{3}$ for virgin vs $0.58 \mathrm{mmol} / \mathrm{cm}^{3}$ for reprocessed ELO/DTBA/DMP30 and $1.84 \mathrm{vs} 0.38 \mathrm{mmol} / \mathrm{cm}^{3}$ for ELO/DTBA/2E4MI, respectively. This result can be attributed to formation of supplementary cross-links with some pending chains. The ELO/DTBA/IM thermosets have the highest values of $\tan \delta$ and cross-linking density before and after reprocessing.

Thermal Stability. The thermal stabilities of virgin and recycled resins were investigated by thermogravimetric analysis (TGA) under air atmosphere (thermal oxidation). The TGA curves as recorded during continuous heating at $10{ }^{\circ} \mathrm{C} \cdot \mathrm{min}^{-1}$ are shown in Figure 6. The degradation process involves a twostages process (Figure S6). For quantitative analysis of the investigated samples, the degradation onset temperature $\left(T_{\text {onset }}\right)$ and the temperature at $5 \%$ weight-loss $\left(T_{5 \%}\right)$ were determined. The main data are summarized in Tables 2 and S6. No degradation occurs before $200{ }^{\circ} \mathrm{C}$ except for noncatalyzed thermoset. In systems with $1 \mathrm{wt} \%$ initiator, the $T_{\text {onset }}$ temperature increases $\sim 50{ }^{\circ} \mathrm{C}\left(\sim 200\right.$ versus $150{ }^{\circ} \mathrm{C}$, Figure 6) and the $T_{5 \%}$ values were shifted to higher temperature from 230 to $275{ }^{\circ} \mathrm{C}$ in the following order: uncatalyzed $<\mathrm{DMP} 30=\mathrm{DMAP}<2-\mathrm{MI}=1-\mathrm{MP}<\mathrm{DMBA}<$ 
Table 2. TGA $T_{5 \%}$ Values of Virgin and Recycled Resins ${ }^{a}$

\begin{tabular}{cccc} 
& \multicolumn{3}{c}{$T_{5 \%}\left({ }^{\circ} \mathrm{C}\right)$} \\
\cline { 2 - 4 } ELO/DTBA systems & virgin & recycled & $\Delta T_{5 \%}$ \\
no initiator & 230 & 220 & -10 \\
IM & 275 & 275 & 0 \\
1-MI & 265 & 267 & 2 \\
2-MI & 250 & 250 & 0 \\
1.2-DMI & 264 & 264 & 0 \\
2E4MI & 260 & 252 & -8 \\
DMBA & 255 & 252 & -3 \\
DMAP & 245 & 245 & 0 \\
DMP30 & 245 & 245 & 0 \\
1-MP & 250 & 245 & -5 \\
TBD & 260 & 260 & 0
\end{tabular}

${ }^{a} \Delta T=T_{5 \% \text {, recycled }}-T_{5 \% \text {, virgin, }} T_{5 \%}=$ temperature for $5 \%$ weight loss determined by TGA

$2 \mathrm{E} 4 \mathrm{MI}=\mathrm{TBD}<1,2-\mathrm{DMI}=1-\mathrm{MI}<\mathrm{IM}$. Very interestingly, as illustrated in Table 2, the $T_{5 \%}$ values were not affected by reprocessing. The only significant decrease of the $T_{5 \%}$ value could be observed for the uncatalyzed and recycled ELO/ DTBA thermoset $\left(T_{5 \%} \approx 220{ }^{\circ} \mathrm{C}\right.$ compared to $230{ }^{\circ} \mathrm{C}$ for virgin thermoset). All virgin and recycled resins were degraded almost completely before $650{ }^{\circ} \mathrm{C}$.

Two degradation steps are observed in the TGA and DTG curves (Figure S6). A similar thermal decomposition behavior was reported by Ding et al. ${ }^{32}$ for ELO/aliphatic dicarboxylic acids/DMAP thermoset. The authors ${ }^{32,46}$ suggest that the first degradation stage involves the breakdown of the estermethylene linkages and of hydroxyls, while at higher temperatures aromatic products are formed. The first degradation step for the virgin and recycled ELO/DTBAcatalyzed thermosets occurs around $\sim 305{ }^{\circ} \mathrm{C}$, except for the ELO/DTBA/DMBA thermoset that starts to degrade at 290 ${ }^{\circ} \mathrm{C}$. This result can be correlated to the lower cross-link degree of this network, as demonstrated previously by DMA analysis.

Study on the Multiple Reprocessing Effect on Materials Performance. The dual dynamic character of the $S-S$ exchanges and of the transesterification reactions improves the ability of materials to be reprocessed. As presented in the previous sections, all of the studied thermosets can be recycled. To evaluate how many times the thermoset can be reprocessed without losing its thermome- chanical properties, the ELO/DTBA/IM thermoset was selected to perform this study because the IM allows the highest conversion rates. Thus, the reprocessing process was performed using the same parameters and repeated 10 times (Figure 7 and Table S6). After several cycles, we observe a slightly dark coloration of the sample, probably due to a partial oxidation and aging. ${ }^{47}$ The properties of recycled materials were investigated by DSC, FTIR, TGA, and DMA analyses. Table 3 summarizes the results of the investigated properties.

Table 3. Thermal and Mechanical Properties of ELO/ DTBA/IM Thermosets after Several Reprocessings

\begin{tabular}{|c|c|c|c|c|c|}
\hline characteristic values & virgin & $\begin{array}{c}1 \text { st } \\
\text { recycling }\end{array}$ & $\begin{array}{l}\text { 2nd } \\
\text { recycling }\end{array}$ & $\begin{array}{c}3 \text { rd } \\
\text { recycling }\end{array}$ & $\begin{array}{c}\text { 10th } \\
\text { recycling }\end{array}$ \\
\hline$T_{\mathrm{g}}^{a}\left({ }^{\circ} \mathrm{C}\right)$ & 76 & 74 & 70 & 64 & 76 \\
\hline$T_{5 \%}^{b}\left({ }^{\circ} \mathrm{C}\right)$ & 275 & 275 & 272 & 273 & 274 \\
\hline $\tan \delta^{c}$ & 89 & 97 & 96 & 91 & 97 \\
\hline$(\tan \delta)_{\max }^{c}$ & 0.68 & 0.82 & 0.82 & 0.79 & 0.83 \\
\hline$E^{\prime c}(\mathrm{MPa})$ at $-50^{\circ} \mathrm{C}$ & 1560 & 1720 & 2500 & 4400 & 6200 \\
\hline$E^{\prime c}(\mathrm{MPa})$ at $150^{\circ} \mathrm{C}$ & 8.6 & 8.9 & 12 & 13.8 & 13 \\
\hline$E^{\prime \prime c} c_{\max }(\mathrm{MPa})$ & 70 & 200 & 200 & 350 & 370 \\
\hline $\begin{array}{l}\text { cross-link density }{ }^{c} \\
\left(\mathrm{mmol} / \mathrm{cm}^{3}\right)\end{array}$ & 1.25 & 0.81 & 1.11 & 1.33 & 1.21 \\
\hline
\end{tabular}

${ }^{a}$ Determined by DSC. ${ }^{b}$ Determined by TGA. ${ }^{c}$ Determined by DMA.

It was found, by scanning DSC, that the glass transition decreases progressively during the reprocessing cycles, from 76 ${ }^{\circ} \mathrm{C}$ in the virgin resin to $64{ }^{\circ} \mathrm{C}$ at the end of the third cycle. This result can be attributed to the continuous $S-S$ exchange during the reprocessing and therefore to network modification. An unexpected result is that at the 10th cycle the resin presents the same $T_{\mathrm{g}}$ value as the virgin resin (Figure $7 \mathrm{~A}$ ). It seems that during the recycling procedure the mechanical properties of the sample decrease, but at certain point there is a reversal of the properties. The dual mechanism of recycling that operates during reprocessing contributes to the increasing cross-linking density and finally regaining the material properties.

The thermal stability of the samples after several recycling stages remains approximately constant, showing very close values of $T_{5 \%}$ even at the end of the 10th reprocessing cycle (Figure $7 \mathrm{~B}$ ). As shown in the DTG thermograms presented in Figure $\mathrm{S} 7$, all of the curves are very similar. The $\tan \delta$ values increase until the third cycle; thereafter, a slight decrease was
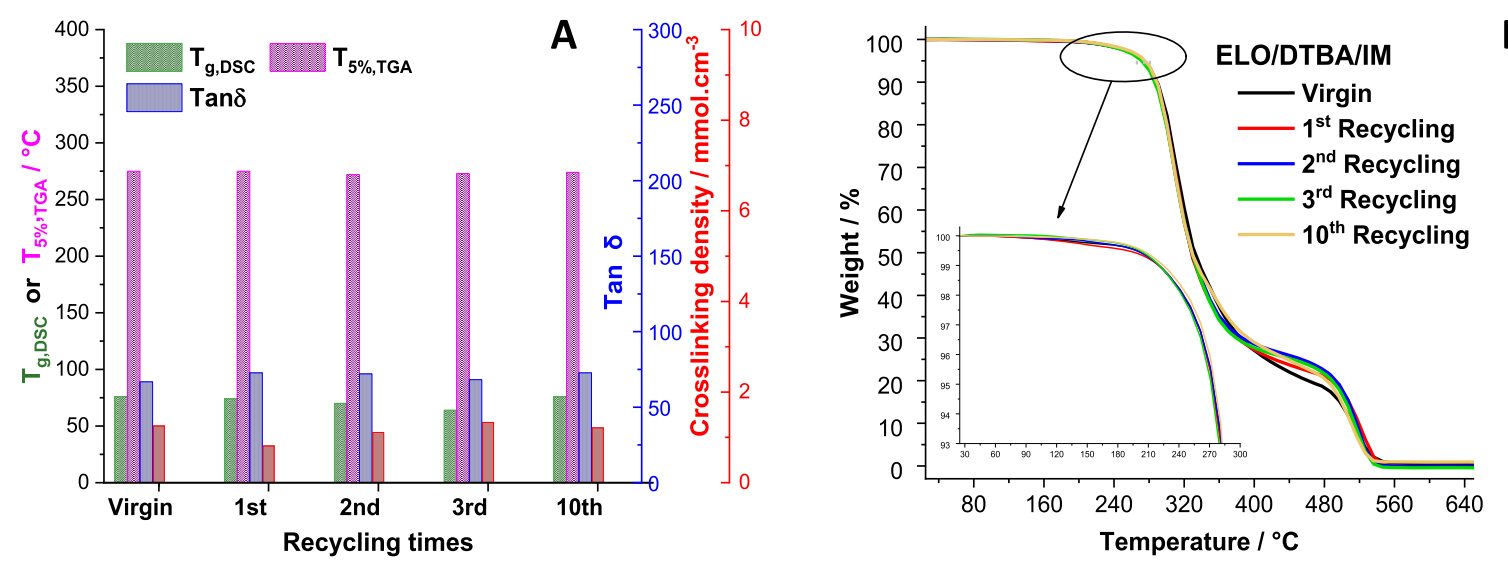

B

Figure 7. (A) Comparison of characteristic values after different reprocessing cycles: $T_{\mathrm{g}}$ (DSC), $T_{5 \%}$ (TGA), $\tan \delta$ (DMA), and cross-linking density calculated by DMA. (B) TGA curves of the virgin and reprocessed ELO/DTBA/IM thermoset. 

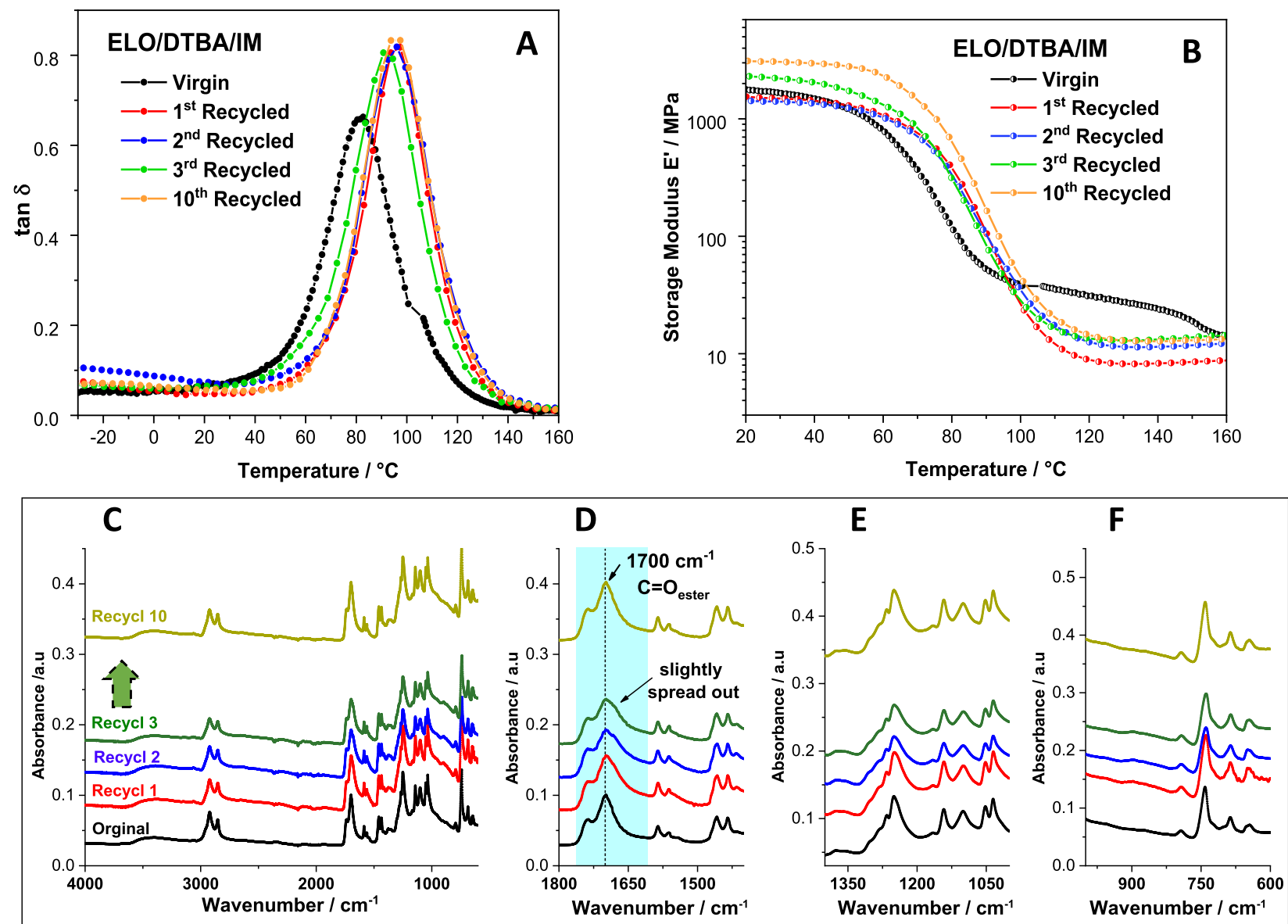

Figure 8. $\tan \delta(\mathrm{A})$ and storage modulus (B) vs temperature; FTIR spectra (C-F) for the virgin and recycled ELO/DTBA/IM.

measured. After the 10th cycle the material has, once again, a similar value to the virgin sample (Figure $7 \mathrm{~A}$ ).

According with the obtained results after the first reprocessing, the $E^{\prime}$ values in glassy state and the $E^{\prime \prime}$ moduli increase by $\sim 4$ or 5 times while the cross-link density remains more or less constant except for its values after the second cycle. These results can be explained as resulting from the dynamic covalent bonds recreating linkages during material recycling. The initial reduction of the cross-linking density after the first reprocessing cycle is restored at the end of the 10th cycle. In fact, after the third cycle, the cross-link density increases again until it reaches the initial value at the end of the 10th recycling. This behavior could be attributed to an internal rearrangement of the thermoset network. Very few changes were observed through the ATR-FTIR spectra in the carbonyl region at $1700 \mathrm{~cm}^{-1}$ (Figure $8 \mathrm{D}$ ). This ester peak seems slightly spread out after the first reprocessing. It suggests the occurrence of transesterification reactions. The 10 times recycled sample has almost an identical structure compared to the virgin one. As the characteristic absorption of the $S-S$ bonds is in the region from 540 to $500 \mathrm{~cm}^{-1}$ (very low frequency), their change during reprocessing is difficult to follow by FTIR.

Swelling Tests. The swelling and solvent stability were tested in several solvents: toluene, acetone, methanol, THF, DMSO, $1 \mathrm{~N} \mathrm{NaOH}, 1 \mathrm{~N} \mathrm{HCl}$ (Figure S9). The timedependent swelling ratio evolution of the prepared thermosets in different solvents reflects the solvent diffusion inside the polymer network.
After $8 \mathrm{~h}$ of immersion in toluene, all samples including virgin and recycled thermosets reached the maximum of the swelling asymptotic curves. Figure 9 shows clearly that the swelling ratio increases in the order IM $<$ DMAP $<$ DMBA $<$ No initiator. The swelling ratio is inversely proportional to the cross-link densities reported in Table 1 . We observed also that after 3 weeks of immersion in toluene at room temperature, all

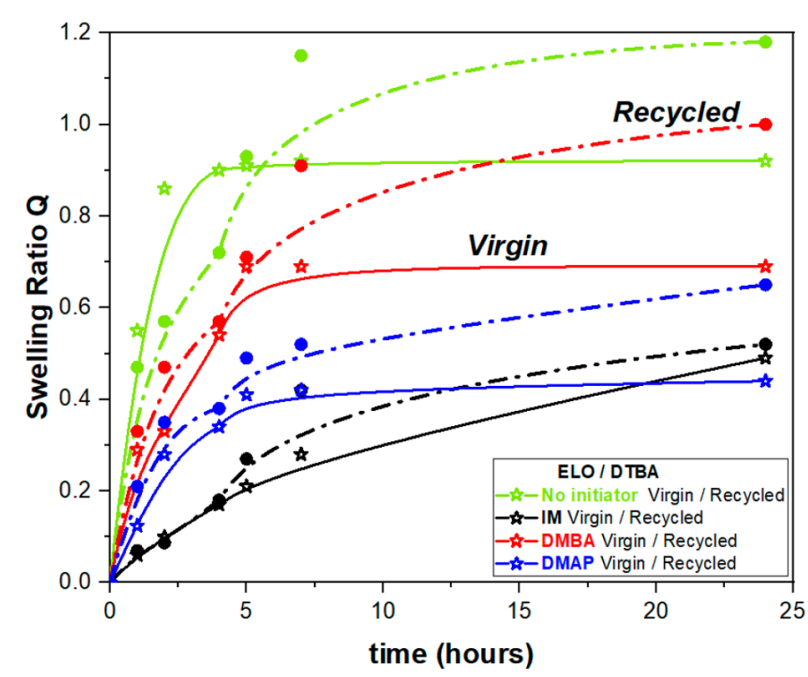

Figure 9. Swelling test in toluene of virgin and reprocessed thermoset resins. 


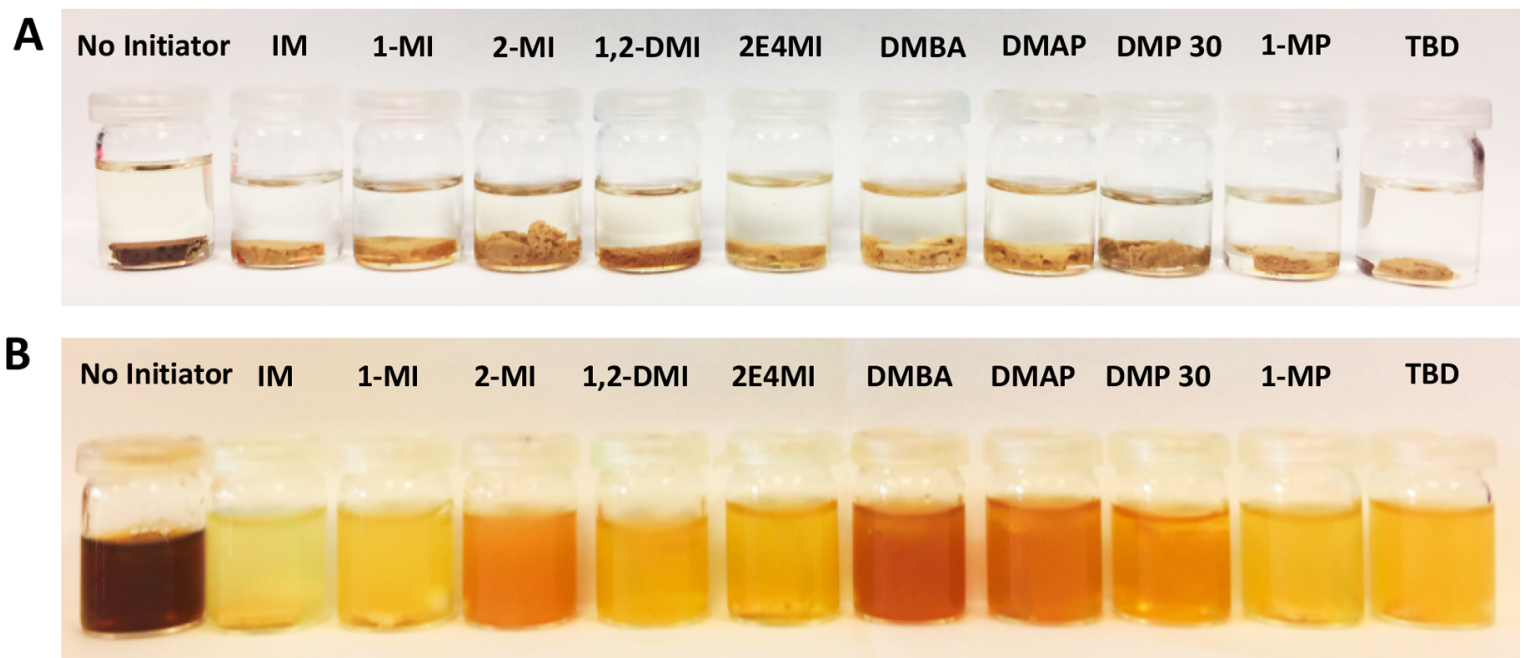

Figure 10. (A) Solvent stability of the ELO/DTBA thermosets in toluene after 3 weeks. (B) Autodegradation in $1 \mathrm{~N} \mathrm{NaOH}$ solution at $80{ }^{\circ} \mathrm{C}$ after 3 days.

of the materials remained unaffected (Figure $10 \mathrm{~A}$ ) without any detected degradation or dissolution. A similar behavior was observed for the test stability in $1 \mathrm{~N} \mathrm{HCl}$.

Concerning the chemical recycling in $1 \mathrm{~N} \mathrm{NaOH}$, very interestingly, all of thr ELO/DTBA thermosets start to lose their integrity after $24 \mathrm{~h}$ at room temperature without the aid of an external compound (Figure 10) and were completely dissolved at $80{ }^{\circ} \mathrm{C}$ after 3 days (Figure $10 \mathrm{~B}$ ) in contrast with the results reported by Ruiz et al. ${ }^{7}$ for an epoxy/disulfide amine thermoset. The authors showed that the obtained thermosets were not degraded in $1 \mathrm{~N} \mathrm{NaOH}$ solution. To completely dissolve the epoxy thermoset, 2-mercaptoethanol as catalyst in DMF organic solvent needed to be added. This observation reflects that the degradation of epoxy resin depends not only on the dissociative nature of the disulfide bonds in alkaline conditions ${ }^{17,44}$ but also on the stability of ester linkages from ELO triglycerides ${ }^{48,49}$ and that of new ester linkages formed during copolymerization. It should be noticed that the decrease in the cross-link density can facilitate complete degradation of thermosets. By lowering the distance between cross-links within the networks, the solvent permeation increases and thus facilitates the polymer-solvent interactions.

\section{CONCLUSIONS}

In this study, the ELO/DTBA copolymerization reaction was studied in the presence of a series of 10 initiators. Their effects on the copolymerization reaction, network properties, and reprocessing were analyzed. The initiator nature impact on the curing mechanism is further reflected in the final properties. The thermosets obtained without initiator have low crosslinking density, low $T_{\mathrm{g}}$, and thermal stability as consequence of a lower functional group conversion. Some initiators failed, such as 1-MP or DMBA, since they produce low copolymerization conversions. For the imidazole series, 2-MI is the least performing on the conversion percentage, producing thermosets that after reprocessing had decreased properties. In the series of heterocyclic initiators, the DMAP allows obtaining materials with excellent properties: one of the highest crosslink densities at the end of the recycling.

Analysis of the materials performance confirms that IM conducts to thermosets with the highest values of conversion percentage, cross-link density, solvent resistance, and thermal stability. These results demonstrate that imidazole is the best initiator for the ELO/DTBA system. The thermal stability and mechanical properties underlined that all of the thermosets can be reprocessed. The materials' properties were kept until the 10th cycle, which is very important considering a further application of these materials. Another important result is the ability of the prepared thermosets to be easily chemically recycled, in suitable solvents, without the need of supplementary chemicals. The biobased thermosets developed in this manuscrpt can have sustainable applications as matrices in reprocessable composites.

\section{ASSOCIATED CONTENT}

\section{Supporting Information}

The Supporting Information is available free of charge at https://pubs.acs.org/doi/10.1021/acssuschemeng.0c01419.

Chemical structures of the selected reagents; curing studies of the reaction with and without initiators by DSC analysis; isothermal ATR-FTIR spectra for ELO/ DTBA thermoset without initiator and with $1 \%$ of imidazole; thermosets and recycled materials characterization by TGA, DMA, and ATR-FTIR; solvent test in 1 $\mathrm{N} \mathrm{NaOH}$ and swelling test in acetone and methanol for the virgin and reprocessed thermoset (PDF)

\section{AUTHOR INFORMATION}

\section{Corresponding Author}

Alice Mija - Université Côte d'Azur, Institut de Chimie de Nice, UMR CNRS 7272, 06108 Nice, Cedex 2, France; ○ orcid.org/0000-0001-5208-5956; Email: Alice.MIJA@ univ-cotedazur.fr

\section{Authors}

Chiara di Mauro - Université Côte d'Azur, Institut de Chimie de Nice, UMR CNRS 7272, 06108 Nice, Cedex 2, France

Thi-Nguyet Tran - Universite Côte d'Azur, Institut de Chimie de Nice, UMR CNRS 7272, 06108 Nice, Cedex 2, France

Alain Graillot - Specific Polymers, 34160 Castries, France

Complete contact information is available at:

https://pubs.acs.org/10.1021/acssuschemeng.0c01419 


\section{Notes}

The authors declare no competing financial interest.

\section{ACKNOWLEDGMENTS}

This work was supported by the ECOXY project. ECOXY is a project funded by the European Commission. This project received funding from the Bio Based Industries Joint Undertaking under the European Union's Horizon 2020 research and innovation program (Grant agreement no. 744311).

\section{ABBREVIATIONS}

ELO, epoxidized linseed oil; DCA, dicarboxylic acids; DTBA, 2,2'-dithiodibenzoic acid; DGEBA, diglycidyl ether of bisphenol A; BPA, bisphenol A; IM, imidazole; 1-MI, 1-methyl imidazole; 2-MI, 2-methyl imidazole; 1,2-DMI, 1,2-dimethylimidazole; 1-MP, 1-methyl-piperazine; 2E4MI, 2-ethyl-4methyl-imidazole; DMBA, $N, N^{\prime}$-dimethyl benzamine; DMAP, dimethylaminopyridine; DMP302, 4,6-tris(dimethylaminomethyl)phenol; TBD, 1,5,7-triazabicyclo[4.4.0] dec-5-ene; FT-IR, Fourier transform infrared spectroscopy; NMR, nuclear magnetic resonance; DSC, differential scanning calorimetry; DMA, dynamic mechanical analysis; TGA, thermogravimetric analysis; DTG, derivative thermogravimetry; vs, versus

\section{REFERENCES}

(1) Liu, T.; Hao, C.; Wang, L.; Li, Y.; Liu, W.; Xin, J.; Zhang, J. Eugenol-Derived Biobased Epoxy: Shape Memory, Repairing, and Recyclability. Macromolecules 2017, 50 (21), 8588-8597.

(2) Yu, K.; Taynton, P.; Zhang, W.; Dunn, M. L.; Qi, H. J. Reprocessing and recycling of thermosetting polymers based on bond exchange reactions. RSC Adv. 2014, 4 (20), 10108-10117.

(3) Baruah, R.; Kumar, A.; Ujjwal, R. R.; Kedia, S.; Ranjan, A.; Ojha, U. Recyclable Thermosets Based on Dynamic Amidation and AzaMichael Addition Chemistry. Macromolecules 2016, 49 (20), 78147824.

(4) Lu, L.; Pan, J.; Li, G. Recyclable high-performance epoxy based on transesterification reaction. J. Mater. Chem. A 2017, 5 (40), 21505-21513.

(5) Azcune, I.; Odriozola, I. Aromatic disulfide crosslinks in polymer systems: Self-healing, reprocessability, recyclability and more. Eur. Polym. J. 2016, 84, 147-160.

(6) Cicala, G.; Pergolizzi, E.; Piscopo, F.; Carbone, D.; Recca, G. Hybrid composites manufactured by resin infusion with a fully recyclable bioepoxy resin. Composites, Part B 2018, 132, 69-76.

(7) Ruiz de Luzuriaga, A.; Martin, R.; Markaide, N.; Rekondo, A.; Cabañero, G.; Rodríguez, J.; Odriozola, I. Epoxy resin with exchangeable disulfide crosslinks to obtain reprocessable, repairable and recyclable fiber-reinforced thermoset composites. Mater. Horiz. 2016, 3 (3), 241-247.

(8) Cicala, G.; Mannino, S.; La Rosa, A. D.; Banatao, D. R.; Pastine, S. J.; Kosinski, S. T.; Scarpa, F. Hybrid biobased recyclable epoxy composites for mass production. Polym. Compos. 2018, 39 (S4), E2217-E2225.

(9) La Rosa, A. D.; Blanco, I.; Banatao, D. R.; Pastine, S. J.; Björklund, A.; Cicala, G. Innovative Chemical Process for Recycling Thermosets Cured with Recyclamines ${ }^{\circledR}$ by Converting Bio-Epoxy Composites in Reusable Thermoplastic-An LCA Study. Materials 2018, 11 (3), 353.

(10) Rowan, S. J.; Cantrill, S. J.; Cousins, G. R. L.; Sanders, J. K. M.; Stoddart, J. F. Dynamic Covalent Chemistry. Angew. Chem., Int. Ed. 2002, 41 (6), 898-952.

(11) Fan, M.; Liu, J.; Li, X.; Zhang, J.; Cheng, J. Recyclable DielsAlder Furan/Maleimide Polymer Networks with Shape Memory Effect. Ind. Eng. Chem. Res. 2014, 53 (42), 16156-16163.
(12) Roy, N.; Bruchmann, B.; Lehn, J.-M. DYNAMERS: dynamic polymers as self-healing materials. Chem. Soc. Rev. 2015, 44 (11), $3786-3807$.

(13) Bowman, C. N.; Kloxin, C. J. Covalent Adaptable Networks: Reversible Bond Structures Incorporated in Polymer Networks. Angew. Chem., Int. Ed. 2012, 51 (18), 4272-4274.

(14) Capelot, M.; Unterlass, M. M.; Tournilhac, F.; Leibler, L. Catalytic Control of the Vitrimer Glass Transition. ACS Macro Lett. 2012, 1 (7), 789-792.

(15) Chen, M.; Zhou, L.; Wu, Y.; Zhao, X.; Zhang, Y. Rapid Stress Relaxation and Moderate Temperature of Malleability Enabled by the Synergy of Disulfide Metathesis and Carboxylate Transesterification in Epoxy Vitrimers. ACS Macro Lett. 2019, 8 (3), 255-260.

(16) Imbernon, L.; Oikonomou, E. K.; Norvez, S.; Leibler, L. Chemically crosslinked yet reprocessable epoxidized natural rubber via thermo-activated disulfide rearrangements. Polym. Chem. 2015, 6 (23), 4271-4278.

(17) Lei, Z. Q.; Xiang, H. P.; Yuan, Y. J.; Rong, M. Z.; Zhang, M. Q. Room-Temperature Self-Healable and Remoldable Cross-linked Polymer Based on the Dynamic Exchange of Disulfide Bonds. Chem. Mater. 2014, 26 (6), 2038-2046.

(18) Kumar, S.; Samal, S. K.; Mohanty, S.; Nayak, S. K. Recent Development of Biobased Epoxy Resins: A Review. Polym.-Plast. Technol. Eng. 2018, 57 (3), 133-155.

(19) Nouailhas, H.; Aouf, C.; Le Guerneve, C.; Caillol, S.; Boutevin, B.; Fulcrand, H. Synthesis and Properties of Biobased Epoxy Resins. Part 1. Glycidylation of Flavonoids by Epichlorohydrin. J. Polym. Sci., Part A: Polym. Chem. 2011, 49, 2261-2270.

(20) Ramon, E.; Sguazzo, C.; Moreira, P. M. G. P. A Review of Recent Research on Bio-Based Epoxy Systems for Engineering Applications and Potentialities in the Aviation Sector. Aerospace. 2018, 5 (4), 110.

(21) Mustapha, R.; Rahmat, A. R.; Abdul Majid, R.; Mustapha, S. N. $H$. Vegetable oil-based epoxy resins and their composites with biobased hardener: a short review. Polym. Plast. Technol. Mater. 2019, 58 (12), 1311-1326.

(22) Rubin, B. S. Bisphenol A: An endocrine disruptor with widespread exposure and multiple effects. J. Steroid Biochem. Mol. Biol. 2011, 127 (1), 27-34.

(23) U.S. Environmental Protection Agency; https://www.epa.gov/ assessing-and-managing-chemicals-under-tsca/bisphenol-bpasummary, 2010.

(24) Almeida, S.; Raposo, A.; Almeida-González, M.; Carrascosa, C. Bisphenol A: Food Exposure and Impact on Human Health. Compr. Rev. Food Sci. Food Saf. 2018, 17 (6), 1503-1517.

(25) Andjelkovic, D.; Valverde, M.; Henna, P.; Li, F. C.; Larock, R. Novel thermosets prepared by cationic copolymerization of various vegetable oils - Synthesis and their structure-property relationships. Polymer 2005, 46, 9674-9685.

(26) Hondred, P. R.; Salat, L.; Mangler, J.; Kessler, M. R. Tung oilbased thermosetting polymers for self-healing applications. J. Appl. Polym. Sci. 2014, 131 (12), 40406-40415.

(27) Pin, J.-M.; Sbirrazzuoli, N.; Mija, A. From Epoxidized Linseed Oil to Bioresin: An Overall Approach of Epoxy/Anhydride CrossLinking. ChemSusChem 2015, 8 (7), 1232-1243.

(28) Ricciardi, F.; Romanchick, W. A.; Joullié, M. M. Mechanism of imidazole catalysis in the curing of epoxy resins. J. Polym. Sci., Polym. Chem. Ed. 1983, 21 (5), 1475-1490.

(29) Heise, M. S.; Martin, G. C. Curing mechanism and thermal properties of epoxy-imidazole systems. Macromolecules 1989, 22, 99104

(30) Yang, S.; Zhang, Q.; Hu, Y.; Ding, G.; Wang, J. Synthesis of maleimide modified imidazole derivatives and their application in one-component epoxy resin systems. Mater. Lett. 2019, 234, 379383.

(31) Liu, L.; Li, M. Curing mechanisms and kinetic analysis of DGEBA cured with a novel imidazole derivative curing agent using DSC techniques. J. Appl. Polym. Sci. 2010, 117 (6), 3220-3227. 
(32) Ding, C.; Shuttleworth, P. S.; Makin, S.; Clark, J. H.; Matharu, A. S. New insights into the curing of epoxidized linseed oil with dicarboxylic acids. Green Chem. 2015, 17 (7), 4000-4008.

(33) Matějka, L.; Pokorný, S.; Dušek, K. Acid curing of epoxy resins. A comparison between the polymerization of diepoxide-diacid and monoepoxide-cyclic anhydride systems. Makromol. Chem. 1985, 186 (10), 2025-2036.

(34) Tran, T.-N.; Di Mauro, C.; Graillot, A.; Mija, A. Chemical reactivity and the influence of initiators on the epoxidized vegetable oil-dicarboxylic acid system. Macromolecules 2020, 53 (7), 25262538.

(35) Liu, Z.; Erhan, S. Ring-Opening Polymerization of Epoxidized Soybean Oil. J. Am. Oil Chem. Soc. 2010, 87 (4), 437-444.

(36) Mahendran, A. R.; Aust, N.; Wuzella, G.; Kandelbauer, A. Synthesis and Characterization of a Bio-Based Resin from Linseed Oil. Macromol. Symp. 2012, 311 (1), 18-27.

(37) Blank, W. J.; He, Z. A.; Picci, M. Catalysis of the epoxy-carboxyl reaction. J. Coat. Technol. 2002, 74 (926), 33-41.

(38) Jang, K.-S.; Eom, Y.-S.; Choi, K.-S.; Bae, H.-C. Crosslinkable Deoxidizing Hybrid Adhesive of Epoxy-Diacid for Electrical Interconnections in Semiconductor Packaging. Polym. Int. 2018, 67 (9), 1241-1247.

(39) Supanchaiyamat, N.; Shuttleworth, P. S.; Hunt, A. J.; Clark, J. H.; Matharu, A. S. Thermosetting resin based on epoxidised linseed oil and bio-derived crosslinker. Green Chem. 2012, 14 (6), 17591765.

(40) Schuchardt, U.; Sercheli, R.; Rogério Matheus, V. Transesterification of vegetable oils: A review. J. Braz. Chem. Soc. 1998, 9 (3), 199-210.

(41) Falco, G.; Sbirrazzuoli, N.; Mija, A. Biomass derived epoxy systems: From reactivity to final properties. Mater. Today Commun. 2019, 21, 100683.

(42) Altuna, F. I.; Espósito, L. H.; Ruseckaite, R. A.; Stefani, P. M. Thermal and mechanical properties of anhydride-cured epoxy resins with different contents of biobased epoxidized soybean oil. J. Appl. Polym. Sci. 2011, 120 (2), 789-798.

(43) Ooi, S. K.; Cook, W. D.; Simon, G. P.; Such, C. H. DSC studies of the curing mechanisms and kinetics of DGEBA using imidazole curing agents. Polymer 2000, 41 (10), 3639-3649.

(44) Ma, Z.; Wang, Y.; Zhu, J.; Yu, J.; Hu, Z. Bio-based epoxy vitrimers: Reprocessibility, controllable shape memory, and degradability. J. Polym. Sci., Part A: Polym. Chem. 2017, 55 (10), 1790-1799.

(45) Gobin, M.; Loulergue, P.; Audic, J.-L.; Lemiègre, L. Synthesis and characterisation of bio-based polyester materials from vegetable oil and short to long chain dicarboxylic acids. Ind. Crops Prod. 2015, 70, 213-220.

(46) Mustata, F.; Tudorachi, N. Thermal behavior of epoxy resin cured with aromatic dicarboxylic acids. J. Therm. Anal. Calorim. 2016, 125 (1), 97-110.

(47) Zhang, H.; Cai, C.; Liu, W.; Li, D.; Zhang, J.; Zhao, N.; Xu, J. Recyclable Polydimethylsiloxane Network Crosslinked by Dynamic Transesterification Reaction. Sci. Rep. 2017, 7 (1), 11833-11842.

(48) Yang, G.; Rohde, B. J.; Robertson, M. L. Hydrolytic degradation and thermal properties of epoxy resins derived from soybean oil. Green Mater. 2013, 1 (2), 125-134.

(49) Shen, M.; Almallahi, R.; Rizvi, Z.; Gonzalez-Martinez, E.; Yang, G.; Robertson, M. L. Accelerated hydrolytic degradation of estercontaining biobased epoxy resins. Polym. Chem. 2019, 10 (23), 32173229. 